\section{Chemische Elemente}

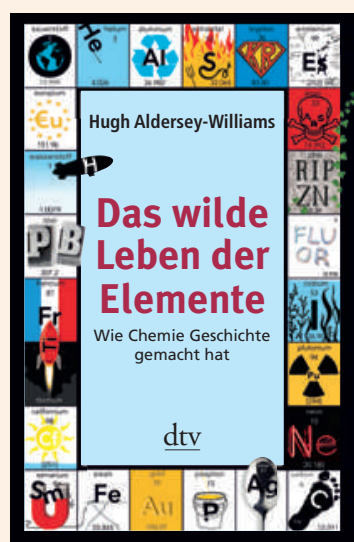

Hugh Aldersey-Williams Das wilde Leben der Elemente

Wie Chemie Geschichte gemacht hat

München: dtv-Taschenbuch; 2013.

460 Seiten. $19.90 \mathrm{CHF}$

ISBN 978-3-4233-4768-6

Englisch:

Periodic tales

The curious lives of the elements

Penguin Books; 2012.

448 Seiten. $18.90 \mathrm{CHF}$

ISBN 978-0-1410-4145-2

Im Periodensystem der Elemente kommt Okkultum nicht vor, obwohl die Theosophen ihre Beobachtungen nach wissenschaftlichen Methoden protokollierten und vom Entdecker des Thalliums beraten wurden. Auch Coronium und Nebulium hat die offizielle Wissenschaft verschmäht. Es half wenig, dass die Forscher subatomare Teilchen postulierten und detaillierte Zeichnungen vorlegten, die erstaunlich den damals berühmten Infusorien von Ernst Haeckel glichen. Die Stationen einer langen Suche nach den Grundbausteinen, aus denen die Welt besteht, hat der englische Chemiker
Hugh Aldersey-Williams zu einer spannenden Kulturgeschichte verwoben. Der Autor widmet rund vierzig Elementen ein Kapitel, angefangen beim Gold bis zum künstlich erzeugten Ununoctium, entsprechend der Ordnungszahl 118, dessen erste Ankündigung zurückgezogen wurde, weil die Daten zum extrem kurzlebigen Edelgasatom gefälscht waren. Nur selten ist die Wissenschaft so unterhaltend und informativ zu haben. Der graue Speisskobold, das arsenhaltige Mineral, aus dem Cobalt stammt, verbirgt eine komplexe Geschichte von Bergwerken, Handelswegen, islamischen Lüsterfarben und Majolikakunst. Das seit 5000 Jahren bekannte Quecksilber faszinierte den ersten Kaiser von China, verleitete seine Ärzte zu einem fatalen Fehlschluss, inspirierte Künstler wie den Regisseur Jean Cocteau zu seiner berühmten Spiegelszene im Kinofilm «Orfée» und Alexander Calder zu einer mobilen Skulptur für den spanischen Pavillon auf der Pariser Weltausstellung 1937. Jedes Element war und ist auch ein kultureller Baustein, ist Teil einer mehr oder weniger blutigen Geschichte, steht für menschliche Schicksale, erfinderische Glanzleistungen und Glücksfälle oder Irrtum, Verrat und Katastrophen.

Das Originalwerk heisst «Periodic Tales - The curious lives of the elements», deutsch mit «Das wilde Leben der Elemente» übersetzt. Die englische Variante kommt dem Buchinhalt näher, denn was der Schein einer Strassenlampe und das Salz auf dem Tisch gemeinsam haben, ist nicht unbedingt wild zu nennen, aber logisch, buchstäblich erhellend und merk-würdig. Das Buch muss nicht der Reihe nach gelesen werden, man kann sich darin kapitelweise sein Lieblingselement heraussuchen, Mineralien und Kristalle nachschlagen, Anekdoten geniessen, geografische Schauplätze im Atlas aufsuchen, und sich, verlockt durch Querverweise, auf lange Umwege des Schmökerns und Staunens begeben. Man kann auch, wie der Autor, die Versuche mittelalterlicher Alchemisten wiederholen und aus dem eigenen Urin Phosphor gewinnen. Was dabei den Apothekerentdecker Hennig Brand mit dem späteren Untergang seiner Heimatstadt verbindet, liest sich wie ein zynischer Witz der Weltgeschichte. Kurz, man soll das Taschenbuch, deutsch oder englisch, lesen, diskutieren oder vorlesen, Vorkenntnisse sind nicht nötig. Bei Medizinern, die keine ausserordentlich gute Chemie-Note hatten, kommt es vielleicht besonders gut an.

Erhard Taverna, Urnäsch 